\title{
SIKAP PERAWAT TERHADAP PASIEN MENJELANG AJAL DAN SIKAP TERHADAP KEMATIAN
}

\author{
Mori Agustina br Perangin-angin, Gallant Deva Nainggolan \\ Fakultas Ilmu Keperawatan Universitas Advent IndonesiaJl Kolonel Masturi no 288 Parongpong, Cihanjuang \\ Rahayu, Bandung Barat \\ Email: mori.peranginangin@unai.edu
}

\begin{abstract}
ABSTRAK
Merawat pasien menjelang ajal merupakan pengalaman yang kurang menyenangkan bagi perawat karena bisa menimbulkan rasa takut, cemas, sedih dan frustasi. Tujuan dari penelitian ini adalah mengetahui hubungan antara sikap perawat pasien menjelang ajal dan sikap terhadap kematian. Metode yang digunakan dalam penelitian ini adalah deskriptif korelasi dengan menggunakan tehnik convinence sampling kepada 95 perawat yang bekerja di Rumah Sakit Advent Bandung. Pengumpulan data dilakukan pada bulan Oktober - November 2019. Untuk mengukur sikap perawat terhadap pasien menjelang ajal digunakan kuesioner Frommelt's Attitude Toward Care of the Dying (FATCOD) scale. Sedangkan untuk mengukur sikap perawat terhadap kematian digunakan kuesioner Death Attittudes Profile-Revised (DAP-R). Hasil penelitian ini menunjukkan bahwa sebagian besar perawat memiliki sikap yang negatif terhadap pasien menjelang ajal (dying attitude) yaitu 83\% dan 81.1\% menunjukkan sikap yang negatif terhadap kematian (death attitude). Hasil uji-t dan uji-F menunjukkan bahwa unit kerja dan pelatihan paliatif mempunyai hubungan yang positif terhadap perawatan menjelang ajal dengan nilai sig< 0.05 . Oleh karena itu penulis menyarankan agar perawat diberikan pelatihan tentang perawatan paliatif agar dapat meningkatkan sikap yang positif dalam merawat pasien menjelang ajal dan sikap terhadap kematian.
\end{abstract}

Kata kunci: kematian; menjelang ajal; sikap perawat

\section{NURSE'S BEHAVIOR TOWARD DEATH AND DYING PATIENT}

\begin{abstract}
Caring for a dying patient is an unpleasant experience because nurses can feel frightened, anxiety, sadness, and frustration. The purpose of this study was to determine the correlation between nurse's behavior towards death and dying patient. Data collection was conducted from October - November 2019 to 95 nurses at Adven Hospital of Bandung using a convenience sampling technique and descriptive correlation method using Frommelt's Attitude toward Care of the Dying (FATCOD) scale and Death Attitudes Profile-Revised (DAP-R) questionnaire. The results of this study indicate that the majority (87.4\%) of nurses have a negative dying attitude, and $81.1 \%$ of nurses have a negative death attitude. F-test and t-test show that the work unit and palliative training have a significant correlation $(s i g<0.05)$ to nurses' dying attitude. Therefore the authors suggest that nurses need to take palliative training to enhance nurses' positive dying attitudes and death attitudes.
\end{abstract}

Keyword: death; dying; nurse attitude 


\section{LATAR BELAKANG}

Perawat memainkan peran yang penting dalam merawat pasien dan keluarga dalam segala fase kehidupan sejak diagnosa ditegakkan hingga menjelang ajal bahkan dalam menghadapi kematian. Perawat lebih banyak menghabiskan waktunya merawat pasien menjelang ajal dibandingkan profesi lain karena perawat adalah profesi yang berada disamping pasien 24 jam dalam sehari.Namun merawat pasien yang sedang menghadapi kematian bukanlah pengalaman yang menyenangkan bagi perawat, tetapi ini merupakan pengalaman yang sulit karena dapat menimbulkankecemasan, stres, sedih dan takut, frustasi, rasa kehilangan (Banu \& Sultan, 2013). Tekanan mental yang cukup besar seringkali dialami perawat ketika menjalani peran dalam merawat pasien menjelang ajal (Mak, Ciang, Chui, 2013).

Faktor yang menyebabkan perasaan tidak nyaman bagi perawat dalam merawat pasien menjelang ajal, seperti keyakinan, agama, suku, tingkat pendidikan, sosial ekonomi, usia dan pengalaman kerja, masalah fisik kondisi psikiatrik, stressor okupasi, pengaruh media dan pengalaman pribadi terkait kematian(Randhawa, 2012; Khader \& Alasad, 2010; Hasheesh, et al., 2013; Neimeyer, et al., 2004 dan Kourakis, 2008 dalam Nia et al., 2016). Merawat pasien menjelang ajal dapat memicu perasaan berduka, merasa gagal, dan hal ini dapat meningkatkan kecemasan di lingkungan kerja (Peterson, et al., 2010).Perasaan cemas ini akan mempengaruhi kemampuan perawat dalam merawat pasien menjelang ajal (Boyle \& Carter, 2013).

Unit kerja perawat juga dapat mempengaruhi sikap perawat dalam merawat pasien menjelang ajal dan sikap terhadap kematian. Perawat yang bekerja di unit keperawatan dimana sering menghadapi kematian seperti di hospis, unit onkologi, atau unit kritisakan menunjukkan rasa cemas yang lebih rendah dibandingkan mereka yang bekerja di unit keperawatan yang jarang kontak dengan pasien menjelang ajal. Penelitian yang dilakukan oleh Dunn, Otten, Stephens (2005) seperti yang dikutip oleh Hasheesh, et al., (2013)menyatakan bahwa perawat yang lebih banyak terpapar atau kontak dengan pasien sekarat memiliki sikap yang lebih positif. Namun tidak ditemukan hubungan yang signifikan antara sikap perawat terhadap kematian dengan sikap dalam merawat pasien sekarat.

Selain itu, faktor lain yang tak kalah penting adalah pelatihan paliatif. Kurangnya kemampuan dan keterampilan yang didapatkan perawat melalui pelatihan paliatif akan membuat perawat tidak siap menghadapi pasien menjelang ajal (Andersson, Salickiene, dan Rosengren, 2016). Kurangnya pendidikan dan pengalaman memberikan kontribusi terhadap sikap yang positif (Banu, Sultan, 2013).Dengan mengikuti pelatihan paliatif akan meningkatkan sikap yang positif bagi perawatdalam merawat pasien menjelang ajal (Matsui \& Braun, 2010).

Sikap perawat terhadap kematian akan mempengaruhi rasa empati dan kualitas pelayanan yang diberikan, serta bagaimana cara mereka mengatasi masalah dalam pekerjaan yang berhubungan dengan stres kematian (Peters et al.,2013).Beberapa hal yang dapat meningkatkan kecemasan perawat dalam merawat pasien menjelang ajal adalah merasa tidak mampu memberikan kenyamanan kepada pasien, merasa terlalu banyak terlibat dengan pasien, takut mengatakan hal yang salah, menjadi perantara antara pasien dan keluarga (Ulla et al., 2003 dalam Nia et al., 2016).

Gesser, Wong, dan Reker (1987) mengembangkan instrumen untuk mengukur sikap terhadap kematian yang dibagi dalam tiga dimensi, yaitu takut kematian (fear of death), penghindaran kematian (death avoidance) serta penerimaan kematian (death acceptance). Takut kematian (fear of death) digambarkan sebagai ketakutan secara sadar dan spesifik terhadap kematian dan ini merupakan ketakutan yang dialami oleh seluruh individu. Beberapa alasan yang membuat seseorang takut terhadap kematian adalah ketakutan kehilangan diri, ketakutan 
yang tidak beralasan, takut mengalami kesakitan dan penderitaan, dan takut akan penderitaan anggota keluarga yang ditinggalkan (Wong, Reker, \&Gesser, 1994).

$$
\text { Penghindaran kematian (death }
$$
avoidance) merupakan sikap yang negatif. Hal ini terjadi ketika seseorang menghindari untuk memikirkan atau membicarakan tentang kematian. Penghindaran kematian sangat kontras dengan takut kematian, dimana seseorang yang takut kematian akan menghadapi kematian dan terikat secara emosional. Penerimaan kematian (death acceptance) merupakan fase akhir dari proses koping terhadap kematian. Secara psikologi kondisi ini merupakan kesiapan individu dalam menghadapi perpisahan dengan kehidupan.

Wong, Reker, \& Gesser, (1994) mengklasifikasikan tiga sikap dalam menerima kematian. Yang pertama adalah penerimaan netral (neutral acceptance), di mana orang memandang dan menerima kematian sebagai bagian integral dari kehidupan. Dia tidak takut mati tetapi juga tidakmenyambut kematian itu. Sikap kedua adalah pendekatan penerimaan (approach acceptance) di mana kematian dianggap sebagai bagian dari akhir yang lebih baik di kehidupan baka.Sikap ketiga adalah penerimaan sebagai kelepasan (escape acceptance), di mana kematian dianggap sebagai kelepasan dari kehidupan yang penuh dengan rasa sakit dan kesedihan sehingga kematian merupakan alternatif kehidupan yang diinginkan.

Pemberian asuhan keperawatan yang berkualitas kepada pasien menjelang ajal, diperlukan komitmen dari dalam diri perawat. Selain itu cara pandang perawat dalam merawat pasien menjelang ajal dan cara pandang terhadap kematian akan membuat perbedaan dalam sikap perawat. Sikap perawat terhadap kematian akan mempengaruhi bagaimana mereka memberikan perawatan pada pasien menjelang ajal.

Tingkat penerimaan perawat terhadap kematian seperti takut kematian, dan penghindaran kematian dapat mempengaruhi sikap mereka terhadap perawatan pasien menjelang ajal. Perawat yang mempunyai rasa cemas dan takut lebih besar terhadap kematianakan menunjukkan sikap positif yang lebih rendah terhadap pasien sekarat dan menjelang ajal dan akan merasa tidak nyaman dalam memberikan asuhan keperawatan pada pasien menjelang ajal. Perawat yang memandang kematian sebagai jalan kelepasan menuju hidup baka akan menunjukkan sikap yang lebih positif dalam memberikan asuhan keperawatan (Dunn, Otten, Stephen, 2005 dalam Hasheesh, et al., 2013).

Rumah Sakit Advent Bandung merupakan salah satu rumah sakit swasta yang memberikan pelayanan kepada pasien dengan berbagai tingkat kompleksitas, termasuk pasien paliatif. Sehingga perawat seringkali harus berhadapan dengan pasien menjelang ajal. Berdasarkan hasil wawancara yang dilakukan kepada beberapa perawat, didapatkan data bahwa terkadang mereka sulit bersikap positif dalam menghadapi kematian pasien.

Perawat juga seringkali merasa kesulitan dalam melakukan komunikasi efektif kepada pasien menjelang ajal dan juga kepada keluarganya. Selain itu masih banyak perawat yang belum pernah mendapat pelatihan paliatif. Oleh karena itu peneliti tertarik untuk melakukan penelitian untuk melihat apakah terdapat hubungan antara antara sikap perawat dalam merawat pasien menjelang ajal dengan sikap dalam merawat pasien sekarat. Selain itu peneliti ingin mengidentifikasi karakteristik perawat yang mempunyai hubungan signifikan dengan sikap dalam merawat pasien menjelang ajal dan sikap terhadap kematian.

\section{METODE}

Penelitian ini merupakan penelitian deskriptif korelasi yang dilakukan kepada 95 orang perawat di Rumah Sakit Advent Bandung. Pengambilan sampel dilakukan dengan metode convenience sampling. Pengumpulan data dilakukan pada bulan Oktober - November 2019 setelah mendapat ijin layak etik dari Komite Etik Universitas Advent Indonesia dengan nomor 026/KEPK-FIK.UNAI/EC/X/19. Analisa univariat dilakukan untuk menentukan 
frekuensi dan persentase. Analisa bivariate dilakukan dengan uji-t dan uji-F untuk melihat perbedaan sikap berdasarkan karakteristik perawat. Instrumen yang digunakan untuk mengukur sikap perawat terhadap kematian adalah kuesioner Death Attittudes ProfileRevised (DAP-R) yang terdiri dari 32 pernyataan yang dibagi menjadi 5 kategori yaitu Fear of Death (7 item), Death Avoidance (5 item), Neutral Acceptance (5 item), Escape Acceptance (5 item), Approach Acceptance (10 item). Kuesioner ini terdiri dari 7 skala Likert. Sedangkan untuk mengukur sikap perawat dalam merawat pasien menjelang ajal digunakan kuesioner Frommelt's Attitude Toward Care of the Dying (FATCOD) Scale (Frommelt, 1991)yang terdiri dari 30 pertanyaan, yaitu14 pernyataan positif $(3,4,7,8,10,12,13,14,15,16,22,26,27,30)$ dan 16 pernyataan negatif $(1,2,5,6,9,11,17,18,19$, $20,21,23,24,25,28,29)$ menggunakan 5 skala Likert yaitu sangat tidak setuju, tidak setuju, ragu ragu, setuju, sangat setuju. Untuk pernyataan positif jawaban sangat tidak setuju diberi skor 1 dan sangat setuju diberi skor 5 .

Sebaliknya untuk pernyataan negatif jawaban sangat tidak setuju diberi skor 5 dan sangat setuju diberi skor 1.Sikap perawat terhadap pasien menjelang ajal dan sikap terhadap kematian dikategorikan ke dalam dua kelompok, yaitu apabila $X>$ mean + 1 SD maka = sikap positif, dan bila $X<$ mean +1 SD = sikap negatif (Sujarweni, 2012).

\section{HASIL}

Distribusi responden berdasarkan jenis kelamin, tingkat pendidikan, lama masa kerja, unit kerja, serta pelatihan paliatif dapat dilihat pada tabel 1.Mayoritas responden adalah berjenis kelamin perempuan (90.5\%), dengan tingkat pendidikan S1 (74.7\%), dan masa kerja $<5$ tahun (35.8\%), serta belum mendapat pelatihan paliatif sebanyak $83.2 \%$

Tabel 1.Distribusi karakteristik responden

\begin{tabular}{llll}
\hline \multicolumn{1}{c}{ Karakteristik Perawat } & Kategori & F & \% \\
\hline Jenis Kelamin & Laki-laki & 9 & 9.5 \\
& Perempuan & 86 & 90.5 \\
\hline Tingkat Pendidikan & Diploma & 23 & 24.2 \\
& Sarjana & 71 & 74.7 \\
& Magister & 1 & 1.1 \\
\hline Lama Bekerja & $1-5$ tahun & 34 & 35.8 \\
& $6-10$ tahun & 19 & 20.0 \\
& $11-15$ tahun & 8 & 8.4 \\
& $16-20$ tahun & 22 & 23.2 \\
& $21-25$ tahun & 4 & 4.2 \\
& $>26$ tahun & 8 & 8.4 \\
\hline Unit kerja & Medikal Bedah & 44 & 46.3 \\
& Kritis & 17 & 17.9 \\
& Pediatrik & 15 & 15.8 \\
& Obstetrik & 6 & 6.3 \\
& Gawat Darurat & 7 & 7.4 \\
& Hemodialisa & 6 & 6.3 \\
\hline Pelatihan Paliatif & Pernah & 16 & 16.8 \\
& Belum pernah & 79 & 83.2 \\
\hline
\end{tabular}


Tabel 2.Persentasi sikap perawat terhadap pasien menjelang ajal dan sikap terhadap kematian

\begin{tabular}{lllllll}
\hline \multirow{2}{*}{$\begin{array}{l}\text { Sikap terhadap pasien menjelang } \\
\text { ajal }\end{array}$} & Mean & SD & $\mathrm{F}$ & $\%$ & \multicolumn{2}{l}{ Kategori } \\
\cline { 2 - 6 } & 106.83 & 8.323 & 12 & 12.6 & $\begin{array}{c}\text { Positif } \\
\text { Negatif }\end{array}$ \\
\hline Sikap terhadap kematian & & & 83 & 87.4 & Positif \\
& 119.88 & 9.926 & 18 & 18.9 & Negatif
\end{tabular}

Data pada tabel 2 menunjukkan bahwa mayoritas perawat (87.4\%) mempunyai sikap yang negatif terhadap pasien menjelang ajal, dan $81.1 \%$ perawat mempunyai sikap yang negatif terhadap kematian.

Tabel 3. Perbedaan sikap perawat berdasarkan jenjang pendidikan

\begin{tabular}{lllllll}
\hline \multicolumn{1}{c}{ Dimensi } & Pendidikan & $\mathrm{n}$ & Mean & SD & F-test & Sig \\
\hline Sikap terhadap & Diploma & 23 & 106.65 & 9.218 & .0349 & .706 \\
pasien menjelang & Sarjana & 71 & 106.99 & 8.104 & & \\
ajal & Magister & 1 & 100.00 & &. & \\
\hline Sikap terhadap & Diploma & 23 & 119.43 & 11.461 & .030 & .970 \\
kematian & Sarjana & 71 & 120.03 & 9.536 & & \\
& Magister & 1 & 120.00 & &. & \\
\hline
\end{tabular}

Data pada tabel 3 menunjukkan bahwa berdasarkan tingkat pendidikan tidak terdapat perbedaan sikap perawat terhadap pasien menjelang ajal dan sikap terhadap kematian baik perawat dengan pendidikan diploma, sarjana dan magister, dengan nilai sig $>0.05$.

Tabel 4. Perbedaan sikap perawat berdasarkan lama kerja

\begin{tabular}{lllllll}
\hline Dimensi & Lama Kerja & $\mathrm{n}$ & Mean & SD & F-Test & Sig \\
\hline Sikap terhadap pasien & 1-5 tahun & 34 & 107.03 & 10.501 & 1.002 & .422 \\
menjelang ajal & 6-10 tahun & 19 & 105.79 & 7.130 & & \\
& 11-15 tahun & 8 & 107.50 & 5.682 & & \\
& $16-20$ tahun & 22 & 108.45 & 7.029 & & .654 \\
& 21-25 tahun & 4 & 110.25 & 5.852 & & \\
& $>26$ tahun & 8 & 101.63 & 5.951 & & \\
Sikap terhadap & 1-5 tahun & 34 & 119.62 & 9.420 & .661 & \\
kematian & 6-10 tahun & 19 & 120.53 & 9.952 & & \\
& $11-15$ tahun & 8 & 124.63 & 10.183 & & \\
& $16-20$ tahun & 22 & 119.82 & 10.391 & & \\
& 21-25 tahun & 4 & 115.25 & 3.202 & & \\
& $>26$ tahun & 8 & 117.25 & 13.069 & & \\
\hline
\end{tabular}

Data pada tabel 4 menunjukkan bahwa berdasarkan lama kerja tidak terdapat perbedaan sikap perawat terhadap pasien menjelang ajal dan sikap terhadap kematian dengan nilai sig $>0.05$. 
Tabel 5. Perbedaan sikap perawat berdasarkan unit kerja

\begin{tabular}{lllllll}
\hline Variabel & Unit Kerja & $n$ & Mean & SD & F-Test & Sig \\
\hline Sikap terhadap & Medikal Bedah & 44 & 107.93 & 7.783 & 2.375 & .045 \\
pasien menjelang & Kritis & 17 & 102.82 & 8.376 & & \\
ajal & Pediatrik & 15 & 110.73 & 8.956 & & \\
& Obstetrik & 6 & 107.33 & 7.312 & & \\
& UGD & 7 & 105.86 & 8.194 & & \\
\hline Sikap terhadap & RU & 6 & 101.00 & 6.753 & & .000 \\
kematian & Medikal Bedah & 44 & 120.34 & 8.983 & 4.989 & \\
& Unit Kritis & 17 & 123.06 & 8.204 & & \\
& Pediatrik & 15 & 117.47 & 9.249 & & \\
& Obstetrik & 6 & 105.33 & 11.272 & & \\
& UGD & 7 & 128.14 & 3.976 & & \\
\hline
\end{tabular}

Data pada tabel 5 dapat dilihat bahwa berdasarkan unit kerjaterdapat perbedaan sikap perawat terhadap pasien menjelang ajal dan sikap terhadap kematiandengan nilai sig<0.05.

Tabel 6. Perbedaan sikap perawat berdasarkan pelatihan paliatif

\begin{tabular}{lllllll}
\hline Dimensi & Pelatihan & $\mathrm{n}$ & Mean & SD & t-test & Sig \\
\hline Sikap terhadap pasien & Pernah & 16 & 110.75 & 8.054 & 2.102 & .038 \\
menjelang ajal & Belum & 79 & 106.04 & 8.202 & & \\
& & & & & & \\
\hline Sikap terhadap kematian & Pernah & 16 & 119.75 & 12.064 & -.059 & .953 \\
& Belum & 79 & 119.91 & 9.526 & & \\
\hline
\end{tabular}

Berdasarkan data pada tabel 6 dapat dilihat bahwa tidak terdapat perbedaan sikap terhadap kematianantara mereka yang sudah mendapat pelatihan paliatif dengan mereka yang belum dengan nilai sig $>0.05$, namun terdapat perbedaan sikap terhadap pasien menjelang ajal antara mereka yang sudah mendapat pelatihan paliatif dengan yang belum mendapat pelatihan dengan nilai sig<0.05.

\section{PEMBAHASAN}

Data yang ditunjukkan pada tabel 2 menunjukkan bahwa mayoritas perawat mempunyai sikap yang negatif terhadap pasien menjelang ajal, dan terhadap kematian. Sikap yang negatif terhadap pasien menjelang ajal menunjukkan perawat masih merasa kurang mampu melakukan komunikasi efektif kepada pasien dan merasa kurang nyaman berada disamping pasien dan membicarakan tentang kematian. Hal ini mendukung apa yang dinyatakan oleh Banu \& Sultan (2013) bahwa merawat pasien menjelang ajal merupakan pengalaman yang dapat menimbulkan perasaan tidak menyenangkan seperti cemas, stress, sedih, takut, frustasi dan rasa kehilangan,bahkan tekanan mental (Mak, Ciang, Chui, 2013). Merawat pasien menjelang ajal juga dapat memicu perasaan berduka dan perasaan gagal (Peterson, et al., 2010).Ada banyak penelitian yang menunjukkan hubungan antara sikap terhadap kematian dengan keinginan untuk membicarakan tentang kematian dan kondisi menjelang ajal. Perawat yang cemas terhadap kematian akan menunjukkan sikap yang negatif dalam merawat pasien menjelang ajal. Ada bukti yang menunjukkan bahwa pelatihan paliatif akan menurunkan kecemasan perawat tentang kematian (Matsui, Braun, 2010). Hasil penelitian ini menunjukkan mayoritas sikap perawat terhadap pasien menjelang ajal dan kematian negatif kemungkinan disebabkan 83.2\% belum pernah mengikuti pelatihan paliatif.

Data pada tabel 3 menunjukkan bahwa tidak terdapat perbedaansikap perawat terhadap pasien menjelang ajal dan sikap terhadap kematian berdasarkan tingkat pendidikan. Hasil ini mendukung penelitian 
yang dilakukan oleh Beckstrand dan Kirchhoff, (2005) seperti yang dikutip oleh Khader, Jarrah dan Alasad (2010) bahwa kurikulum keperawatan yang ada kurang mempersiapkan mahasiswa perawat dalam memberikan perawatan akhir hayat. Persiapan yang cukup melalui program pendidikan akan meningkatkan sikap positif dan dapat meningkatkan kontrol terhadap emosi mereka.

Oleh karena itu perlu untuk menambahkan subjek tentang perawatan menjelang ajal dalam kurikulum keperawatan. $\mathrm{Hal}$ ini juga terlihat pada kurikulum keperawatan di Indonesia bahwa mata ajar keperawatan paliatif baru muncul di kurikulum AEPNI 2015 sebagai salah satu mata ajar yang wajib diterima oleh mahasiswa keperawatan. Ini berarti perawat yang telah menyelesaikan pendidikan sebelum tahun 2015 belum mendapatkan mata ajar keperawatan paliatif. $\mathrm{Hal}$ ini membuat pengetahuan perawat tentang perawatan paliatif masih kurang memadai. Hasil ini berbeda dengan hasil penelitian Ali dan Ayoub (2010) bahwa tingkat pendidikan mempunyai hubungan yang signifikan dengan sikap perawat dalam merawat pasien menjelang ajal. Hal ini kemungkinan disebabkan perawat yang diteliti pernah mengikuti pelatihan paliatif sebagai tambahan pengetahuan yang lebih berfokus pada perawatan pasien menjelang ajal.

Data pada tabel 4 menunjukkan bahwa lama kerja tidak membuat perbedaan sikap perawat terhadap pasien menjelang ajal dan sikap terhadap kematian. Ini sesuai dengan hasil penelitian yang dilakukan oleh Ali dan Ayoub (2010) terhadap 197 perawat onkologi di Mansoura University Hospital Mesir bahwa tidak terdapat hubungan yang signifikan antara lama kerja dengan sikap dalam merawat pasien menjelang ajal. Hal ini bisa saja disebabkan oleh karena walaupun seorang perawat mempunyai pengalaman yang sudah lama bekerja sebagai perawat namun dalam pekerjaan sehari hari mungkin jarang berhadapan dengan pasien menjelang ajal.Namun hasil ini bertolak belakang dengan hasil penelitian Malliarou, et al.,(2011) menunjukkan bahwa lama kerja merupakan indikator paling kuat yang tampak dalam diri perawat yang bersikap positif dalam merawat pasien menjelang ajal. Hal ini berarti semakin lama masa kerja perawat akan menunjukkan sikap yang lebih positif.

Data pada tabel 5 menunjukkan bahwa berdasarkan unit kerja terdapat perbedaan sikap perawatterhadap pasien menjelang ajal dan sikap terhadap kematian.Hal ini sesuai dengan penelitian yang dilakukan oleh Seo, et al., (2013) kepada perawat di UGD, ICU dan departemen onkologi yang menunjukkan perbedaan sikap yang signifikan berdasarkan unit kerja. Perawat yang bekerja di unit perawatan yang banyak terpapar dan berhubungan dengan pasien menjelang ajal akan mempunyai sikap yang lebih positif terhadap kematian dan pasien menjelang ajal (Dunn, Otten, Stephens, 2005 dalam Hasheesh, et al.,2013).Namun hasil ini berbeda dengan penelitian Matsui \& Braun, (2010) yang menunjukkan bahwa unit kerja tidak ada hubungannya dengan sikap dalam merawat pasien menjelang ajal. Perlu dikaji lebih dalam faktor faktor yang mempengaruhi hal ini.

Data pada tabel 6 menunjukkan bahwa tidak terdapat perbedaan sikap terhadap kematianantara mereka yang sudah mendapat pelatihan paliatif dengan mereka yang belum, namun terdapat perbedaan sikap terhadap pasien menjelang ajal antara mereka yang sudah mendapat pelatihan paliatif dengan yang belum mendapat pelatihan. Merawat pasien dengan penyakit serius membutuhkan pengetahuan dan ketrampilan khusus. Kurangnya kemampuan dan keterampilan yang didapatkan perawat melalui pelatihan paliatif akan membuat perawat tidak siap menghadapi pasien menjelang ajal (Andersson, Salickiene, dan Rosengren, 2016). Pelatihan paliatif menjadi faktor yang mempengaruhi sikap dalam merawat pasien menjelang ajal (Matsui, Braun, 2014; Wang, Li, Zhang, Jie, 2018). Ada banyak hasil penelitian menunjukkan bahwa pelatihan dapat merubah sikap perawat menjadi lebih positif terhadap pasien menjelang ajal. Pelatihan juga dapat mencegah 
koping maladaptif serta mengurangi kecemasan perawat (Goris et al.,2017); Seo, et al.,(2013). Selain mendapatkan pelatihan paliatif, perlu juga dikaji lebih dalam durasi pelatihan yang diikuti serta materi yang diterima.

\section{KESIMPULAN DAN SARAN}

Hasil penelitian ini menunjukkan bahwapelatihan paliatif sangat diperlukan untuk meningkatkan sikap perawat menjadilebih positif dalam merawat pasien menjelang ajal dan dalam menyikapi kematian.Oleh karena itu penulis menyarankan agar pihak yang berwenang dapat memfasilitasi perawat dalam mengikuti pelatihan paliatif dan sejenisnya.

\section{REFERENSI}

Ali W.G.M., Ayoub N.S., (2010). Nurses' attitudes toward caring for dying patient in Mansoura University Hospital. Journal of Medicine and Biomedical Sciences, ISSN: 20780273

Anderssona, E., Salickiene, Z. \& Rosengren, K. (2016). To be involved: A qualitative study of nurses' experiences of caring for dying patients. Nurse Education Today, Volume 38, Pages 144-149.

Banu Cevik \& Sultan Kav. (2013). Attitudes and experiences of nurses toward death and caring for dying patients in Turkey. Cancer Nursing, 36 (6) - p E58-E65

Boyle, M., Carter, D.E. (2013).Death anxiety amongst nurses.International Journal of Palliative Nursing, volumel. 4, No. 1

Braun M., Gordon D., Uziely B., (2010).Associations between oncology nurses' attitudes toward death and caring for dying patients. Oncology Nursing Forum, 37(1)

Frommelt, K.H. (1991). The effects of death education on nurses' attitudes toward caring for terminally ill persons and their families. American Journal of Hospice and Palliative Care, 8(5), 37-43.
Gesser, G., Wong, P.T.P., \& Reker, G.T. (1987).Death attitudes across the lifespan: The development and validation of the death attitude Profile (DAP). Omega: Journal of Death and Dying, 18, 113-128

Göriş S.,Taşcı S., Özkan B., Ceyhan Ö., Kartın P.T., Çeliksoy A., Elmalı F., \& Eser B., (2017). Effect of terminal patient care training on the nurses' attitudes toward death in an oncology hospital in Turkey. Journal of Cancer Education, 32, pages 65-71

Hasheesh, M.O.A., AboZeid, S.A., El-Said, S.G., Alhujaili, A.D. (2013). Nurses' characteristics and their attitudes toward death and caring for dying patients in a public hospital in Jordan. Health Science Journal, 7 (4).

Khader K, Jarrah S, Alasad J., (2010). Influences of nurses' characteristics and education on their attitudes towards death and dying: $A$ review of literature. International Journal of Nursing and Midwifery, volume 2(1), pages 1-9.

Mak, Y.W., Chiang, V.C.A., \& Chui, W.T. (2013). Experiences and perceptions of nurses caring for dying patients and families in the acute medical admission setting. International Journal of Palliative Nursing, vol. 19

Matsui M, Braun K. (2010). Nurses' and care workers' attitudes toward death and caring for dying older adults in Japan. Int J Palliat Nurs, 16: 593-8

Matsui, M., \&Braun, K. (2014). Nurses' and care workers' attitudes toward death and caring for dying older adults in Japan. International Journal of Palliative Nusing. 16 (12).

Nia, H.S., Lehto, R.H., Ebadi, A., Peyrovi, H. (2016). Death anxiety among nurses and health care professionals: A review article. Int $\mathrm{J}$ Community Based Nurs Midwifery

Peters L, Cant R, Payne S, et al. 2013. How Death anxiety impacts nurses' caring for patients at the end of life: $A$ 
review of literature. The Open Nursing Journal.Vol;7:14-21.

Peterson J, Johnson MA, Halvorsen B, et al., (2010). What is it so stressful about caring for a dying patient? A qualitative study of nurses' experiences. International Journal of Palliative Nursing. 2010;16:181-7.

Seo M., Kim J.Y, Kim S., Lee T.W. (2013). Nurses attitudes toward death, coping with death and understanding and performance regarding EOL care: Focus on nurses at ED, ICU and oncology department. The Korean Journal of Hospice and Palliative Care, 16(2), Pages.108117
Sujarweni, Wiratna, (2012). SPSS Untuk Paramedis. Yogyakarta. Gava Media

Wang L., Li C., Zhang Q., Jie, Y. (2018). Clinical nurses' attitudes towards death and caring for dying patients in China. International Journal of Palliative Nursing. 24 (1)

Wong, T.P., Reker, G.T., \& Gesser, G. (1994). Death attitude profile-revised: A multi dimensional measure of attitudes toward death. In R.A. Neimeyer (Ed.), Death anxiety handbook: Research, instrumentation

Zyga S., Malliarou M., Lavdaniti M., Athanasopoulou M., Sarafis P., (2011). Greek renal nurses' attitudes towards death. Journal of Renal Care 37(2), 100-107. 